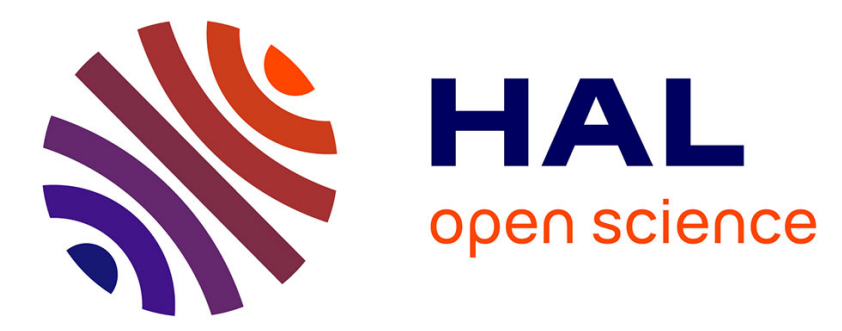

\title{
CAST3M/ARCTURUS: A coupled heat transfer CFD code for thermal-hydraulic analyzes of gas cooled reactors
}

E. Studer, A. Beccantini, S. Gounand, F. Dabbene, Jp. P Magnaud, H. Paillere, I. Limaiem, F. Damian, H. Golfier, C. Bassi, et al.

\section{To cite this version:}

E. Studer, A. Beccantini, S. Gounand, F. Dabbene, Jp. P Magnaud, et al.. CAST3M/ARCTURUS: A coupled heat transfer CFD code for thermal-hydraulic analyzes of gas cooled reactors. Nuclear Engineering and Design, 2006, 237 (15-17), pp.1814-1828. 10.1016/j.nucengdes.2007.03.016 . cea02355754

\author{
HAL Id: cea-02355754 \\ https://hal-cea.archives-ouvertes.fr/cea-02355754
}

Submitted on 9 Dec 2019

HAL is a multi-disciplinary open access archive for the deposit and dissemination of scientific research documents, whether they are published or not. The documents may come from teaching and research institutions in France or abroad, or from public or private research centers.
L'archive ouverte pluridisciplinaire HAL, est destinée au dépôt et à la diffusion de documents scientifiques de niveau recherche, publiés ou non, émanant des établissements d'enseignement et de recherche français ou étrangers, des laboratoires publics ou privés. 


\title{
CAST3M/ARCTURUS: A coupled heat transfer CFD code for thermal-hydraulic analyzes of gas cooled reactors
}

\author{
E. Studer ${ }^{\text {a,* }}$, A. Beccantini ${ }^{\text {a }}$, S. Gounand ${ }^{\text {a }}$, F. Dabbene ${ }^{\text {a }}$, J.P. Magnaud ${ }^{\text {a }}$, H. Paillère $^{\text {a }}$, \\ I. Limaiem ${ }^{\text {b }}$, F. Damian ${ }^{\text {b }}$, H. Golfier ${ }^{\text {b }}$, C. Bassi ${ }^{\text {c }}$, J.C. Garnier ${ }^{\mathrm{c}}$ \\ ${ }^{a}$ C.E.A. Saclay, Heat Transfer \& Fluid Mechanics Laboratory, DM2S/SFME/LTMF, 91191 Gif-sur-Yvette Cedex, France \\ ${ }^{\mathrm{b}}$ C.E.A. Saclay, Advanced Concept Laboratory, DM2S/SERMA/LCA, 91191 Gif-sur-Yvette Cedex, France \\ ${ }^{c}$ C.E.A. Cadarache, Innovative Systems Design Laboratory, DER/SESI/LCSI, 13108 Saint-Paul-lez-Durance Cedex, France
}

Received 25 April 2006; received in revised form 6 March 2007; accepted 6 March 2007

\begin{abstract}
The safety of gas cooled reactors (High Temperature Reactors (HTR), Very High Temperature Reactors (VHTR) or Gas Cooled Fast Reactors (GFR)) must be ensured by systems (active or passive) which maintain loads on component (fuel) and structures (vessel, containment) within acceptable limits under accidental conditions. To achieve this objective, thermal-hydraulics computer codes are necessary tools to design, enhance the performance and ensure a high safety level of the different reactors. Some key safety questions are related to the evaluation of decay heat removal and containment pressure and thermal loads. This requires accurate simulations of conduction, convection, thermal radiation transfers and energy storage. Coupling with neutronics is also an important modeling aspect for the determination of representative parameters such as neutronics coefficient (Doppler coefficient, Moderator coeffcient, ... ), critical position of control rods, reactivity insertion aspects, .... For GFR, the high power density of the core and its necessary reduced dimension cannot rely only on passive systems for decay heat removal. Therefore, forced convection using active safety systems (gas blowers, heat exchangers, ...) are highly recommended. Nevertheless, in case of station black-out, the safety demonstration of the concept should be guaranteed by natural circulation heat removal. This could be performed by keeping a relatively high back-up pressure for pure helium convection and also by heavy gas injection. So, it is also necessary to model mixing of different gases, the on-set of natural convection and the pressure and thermal loads onto the proximate or guard containment. In this paper, we report on the developments of the CAST3M/ARCTURUS thermal-hydraulics (Lumped Parameter and CFD) code developed at CEA, including its coupling to the neutronics code CRONOS2 and the system code CATHARE. Elementary validation cases are detailed, as well as application of the code to benchmark problems such as the HTR-10 thermal-hydraulic exercise. Examples of containment thermal-hydraulics calculations for fast reactor design (GFR) are also detailed. (C) 2007 Elsevier B.V. All rights reserved.
\end{abstract}

\section{Introduction}

The safety of gas cooled reactors must be ensured by active or passive systems which fulfill the task of keeping loads on component (fuel) and structures (vessel, containment) within acceptable limits under accidental conditions at all moments. To achieve this objective, thermal-hydraulics computer codes are necessary tools to design, enhance the performance and ensure a high safety level of the different reactors. ARCTURUS is a multi-dimensional (2D and 3D) heat transfer and thermal-hydraulics simulation tool developed by CEA for appli-

\footnotetext{
* Corresponding author.

E-mail address: etienne.studer@cea.fr (E. Studer).
}

cations to gas cooled reactors. Models, elementary test cases, benchmark exercises and applications are developed and consolidated in the CAST3M platform environment, which is a general purpose structural and fluid mechanics code. The first version of ARCTURUS was released 2 years ago (Studer and Coulon, 2003) and was applied to the High Temperature Engineering Reactor (HTTR) Vessel Cooling benchmark and MHTGR steady state calculations. Some new developments, verifications and applications are reported in the present article.

The first section is dedicated to GFR containment analyses of a depressurization accident. This includes the development of a lumped parameter thermal-hydraulics analyses using a depressurization accident scenario coming from CATHARE code simulations. The second section focuses on GCR invessel thermal-hydraulics including the description of the 


\begin{tabular}{|c|c|}
\hline \multicolumn{2}{|c|}{ Nomenclature } \\
\hline$C p$ & heat capacity \\
\hline$d_{\mathrm{H}}$ & hydraulic diameter \\
\hline$f$ & pressure loss coefficient \\
\hline$F$ & friction term \\
\hline$g$ & gravity \\
\hline$G r$ & Grashof number \\
\hline$h$ & heat exchange coefficient \\
\hline$K$ & friction coefficient \\
\hline$L$ & length \\
\hline $\mathrm{Nu}$ & Nusselt number \\
\hline$p^{\prime}$ & dynamic pressure \\
\hline$P$ & pressure \\
\hline $\operatorname{Pr}$ & Prandtl number \\
\hline$Q$ & mass flow rate \\
\hline $\operatorname{Re}$ & Reynolds number \\
\hline$S$ & area \\
\hline$t$ & time \\
\hline$T$ & temperature \\
\hline$u, v, w$ & fluid velocity \\
\hline$V$ & volume \\
\hline$W$ & volumetric heat source \\
\hline$x, y, z$ & spatial coordinates \\
\hline$Y$ & mass fraction \\
\hline \multicolumn{2}{|c|}{ Greek letters } \\
\hline$\varepsilon$ or $\beta$ & porosity (fluid volume/total volume) \\
\hline$\phi_{\text {neutro }}$ & neutronic heat flux \\
\hline$\phi_{\mathrm{rad}}$ & radiative heat flux \\
\hline$\gamma$ & isentropic coefficient \\
\hline$\lambda$ & heat conductivity \\
\hline$\mu$ & dynamic viscosity \\
\hline$\rho$ & density \\
\hline$\rho_{\mathrm{f}}$ & fluid density \\
\hline \multicolumn{2}{|c|}{ Subscripts } \\
\hline $\mathrm{cr}$ & critical \\
\hline $\mathrm{D}$ & homogenized value \\
\hline eq & equivalent \\
\hline $\mathrm{f}$ & fluid \\
\hline in & Inlet \\
\hline$j, k$ & LP compartment number \\
\hline$l$ & gaseous specie \\
\hline $\mathrm{m}$ & mean value \\
\hline out & outlet \\
\hline $\mathrm{s}$ & solid \\
\hline $\mathrm{T}$ & turbulent contribution \\
\hline $1,2,3$ & location in the simplified depressurization model \\
\hline
\end{tabular}

ARCTURUS "equivalent porous media" and 1D fluid/3D thermal models, elementary verification of these models and application to the HTR-10 benchmark exercise. In the third section, we describe some coupling analyses between thermal-hydraulics and neutronics for HTR reactors in order to investigate the importance of the various parameters in feedback calculations. Conclusions follow.

\section{GFR Containment thermal-hydraulics}

\subsection{Objectives}

Current concepts of Gas Cooled Fast Reactors use helium gas as coolant under about 70 bars of total pressure. Reactor vessel depressurization accident is one of the accidents that has to be considered to design the reactor core and the safety systems. The advantages of helium gas drastically disappear when the pressure decreases. So, as far as passive residual heat removal is concerned, helium is not the most interesting gas unless a sufficient pressure is maintained within the reactor vessel (including the guard containment) or a heavier gas is added. A leak-tight containment is first chosen to prevent any off-site radioactive release in post-accidental situations. An important safety issue is to properly justify the containment (pre)design, taking into account the thermal and mechanical loadings which could occur in postulated depressurization accidents. In previous exploratory studies (Poette, 2004; Dumaz et al., 2005), the containment also had the safety function described above which is to ensure, in depressurization accidents, a back-up pressure high enough to cool the core with pure gas natural circulation (guard containment option for passive decay heat removal). Therefore, the guard containment consists in a pre-stressed concrete structure - single-cavity cylinder, as close as possible to the primary circuit. It is (pre)designed to sustain a static pressure of about $2 \mathrm{MPa}$, whereas, in normal operating conditions, it is pressurized with dry air at about $1.4 \mathrm{MPa}$ (therefore allowing for potential pressure increase in accidental conditions). The objective of the present study is two-fold:

- to prepare and test a preliminary model of the thermalhydraulics phenomena in the guard containment looking at heat transfer to the walls and structures and pressure evolution versus time,

- to consolidate the design presented in Poette (2004) by performing some scoping studies.

The studies are conducted with the ARCTURUS code using boundary conditions (mass and energy flow rates into the containment) coming from CATHARE system code calculations. In the first part, the design of the $600 \mathrm{MW}$ GFR containment including free volumes, walls area, flow paths between different volumes is described. These data are a necessary part of the containment code input deck and the lumped parameter approach adopted for the ARCTURUS code is also briefly described in the same section. Then, the second part is devoted to an analysis of a CATHARE depressurization scenario (1 in. break Loss-OfCoolant Accident (LOCA) cumulated with station black-out).

\subsection{Containment geometry and lumped parameter model description}

A general presentation of the $600 \mathrm{MW}$ GFR reactor is presented in Fig. 1. The containment is mainly divided into four 


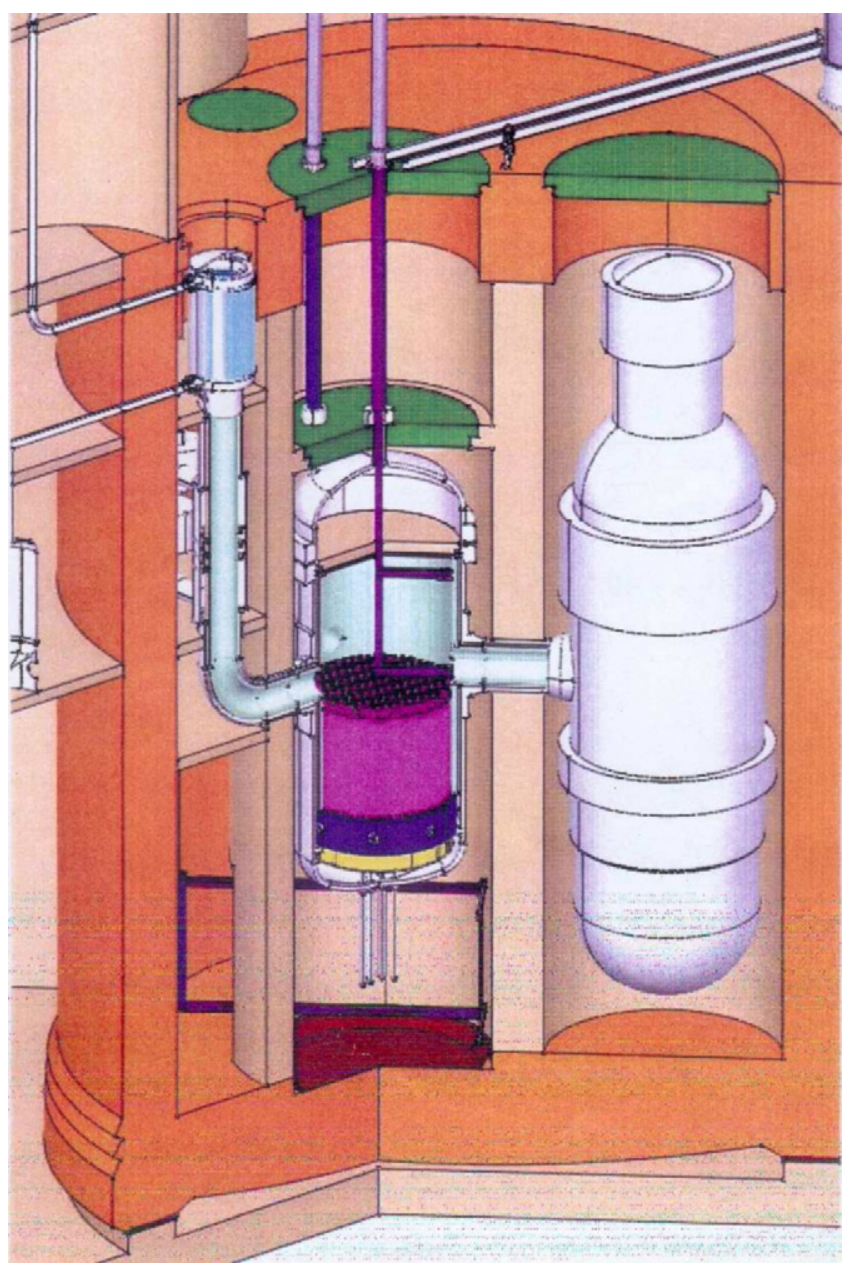

Fig. 1. GFR $600 \mathrm{MW}$ concept: general view of the containment.

main compartments: the reactor pit with the reactor vessel inside, the compartment above the reactor pit with the control rods mechanisms, the Power Conversion System (PCS) compartment including mainly the gas turbine, and a surrounding compartment with the Residual Heat Removal System (RHRS composed of three heat exchangers). These fluid volumes are enclosed by concrete walls and the different volumes are connected through atmospheric junctions (doors, stairs, ....). All this system is included in a reinforced concrete containment of about $14000 \mathrm{~m}^{3}$. In Table 1, the main characteristics of this containment are reported including free gaseous and heat slabs volumes. The ARCTURUS Lumped Parameter (LP) approach of the reactor containment fluid mechanics is based on mass and

Table 1

GFR 600 MW concept: summary of containment volumes

\begin{tabular}{lc}
\hline Name & Volume $\left(\mathrm{m}^{3}\right)$ \\
\hline Free gas volume & 13,560 \\
Concrete basemat & 2128 \\
Concrete inner walls & 2984 \\
Concrete decks & 1920 \\
Steel plugs & 67 \\
Steel liner & 19.9 \\
Concrete containment & 9388 \\
\hline
\end{tabular}

energy balance in sub-compartment and an inertia type equation is solved to connect together the different sub-compartments (Studer and Dabbene, 2003).

$$
\begin{aligned}
& V_{k} \frac{\mathrm{d} \rho_{k}^{l}}{\mathrm{~d} t}+\sum_{j}\left[\frac{\rho_{k j}^{l}}{\rho_{k j}} Q_{k j}\right]=0 \\
& \rho_{k}-\sum_{l} \rho_{k}^{l}=0 \\
& \frac{L_{k j}}{S_{k j}} \frac{\mathrm{d} Q_{k j}}{\mathrm{~d} t}+\left(p_{j}-p_{k}\right)+\frac{K_{k j}\left|Q_{k j}\right| Q_{k j}}{2 \rho_{k j} S_{k j}^{2}}-\rho_{k} g\left(z_{k}-z_{k j}\right) \\
& \quad+\rho_{j} g\left(z_{j}-z_{k j}\right)=0
\end{aligned}
$$

$\frac{\mathrm{d} \rho_{k} V_{k} e_{k}}{\mathrm{~d} t}+\sum_{j}\left[h_{k j} Q_{k j}\right]=0$

where $V_{k}$ represents the volume of compartment $k, \rho_{k j}^{l}$ the density of species $l$ in the junction between compartment $k$ and $j$, $\rho_{k j}$ the total mass density in this junction, $Q_{k j}$ the total mass flow rate through the junction and $\rho_{k}^{l}$ the density of species $l$ in the compartment $k$. In the momentum equation, $K_{k j}$ represents a friction coefficient in the junction between compartment $k$ and $j$, of area $S_{k j}$ and length $L_{k j}$, and $z$ is the vertical coordinate.

A free volume enclosed in concrete walls may be divided in several sub-compartments in order to describe the flow pattern inside the containment. Usually, the sub-grid of the lumped parameter approach is constructed by engineering judgment and often verified by some CFD simulations. In the present study, this last item has not been performed because we are at the design stage and many hypotheses have already been taken into account due to the lack of information regarding the design drawings. Nevertheless, the experience gained by simulating Pressurized Water Reactor (PWR) containment thermal-hydraulics (Studer and Dabbene, 2003) can be applied to GFR containment. A schematic view of the proposed nodalization of the GFR $600 \mathrm{MW}$ containment is given in Figs. 2 and 3. The reactor cavity and the PCS containment are divided in two radial sectors and five axial levels. The three axial levels between $+8 \mathrm{~m}$ and $+24 \mathrm{~m}$ for the cavity or $+27.5 \mathrm{~m}$ for the PCS compartment are composed of an inner zone close to the vessels and an outer zone close to the concrete walls. The RHRS compartment is also composed of five axial levels but four radial sectors (only 3 have a RHRS heat exchanger). The control rods compartment is discretized with a single gaseous volume. Finally, 45 compartments are used to describe the gaseous volume of the containment. Four different kinds of heat slabs are considered in the present model:

- the steel plugs;

- the concrete inner walls;

- the component walls (reactor vessel, PCS, RHRS exchangers and pipes) used as thermal boundary conditions;

- the outer containment walls composed of three layers: a steel liner of $6 \mathrm{~mm}$, an air gap of $1 \mathrm{~mm}$ and finally the external concrete wall. 


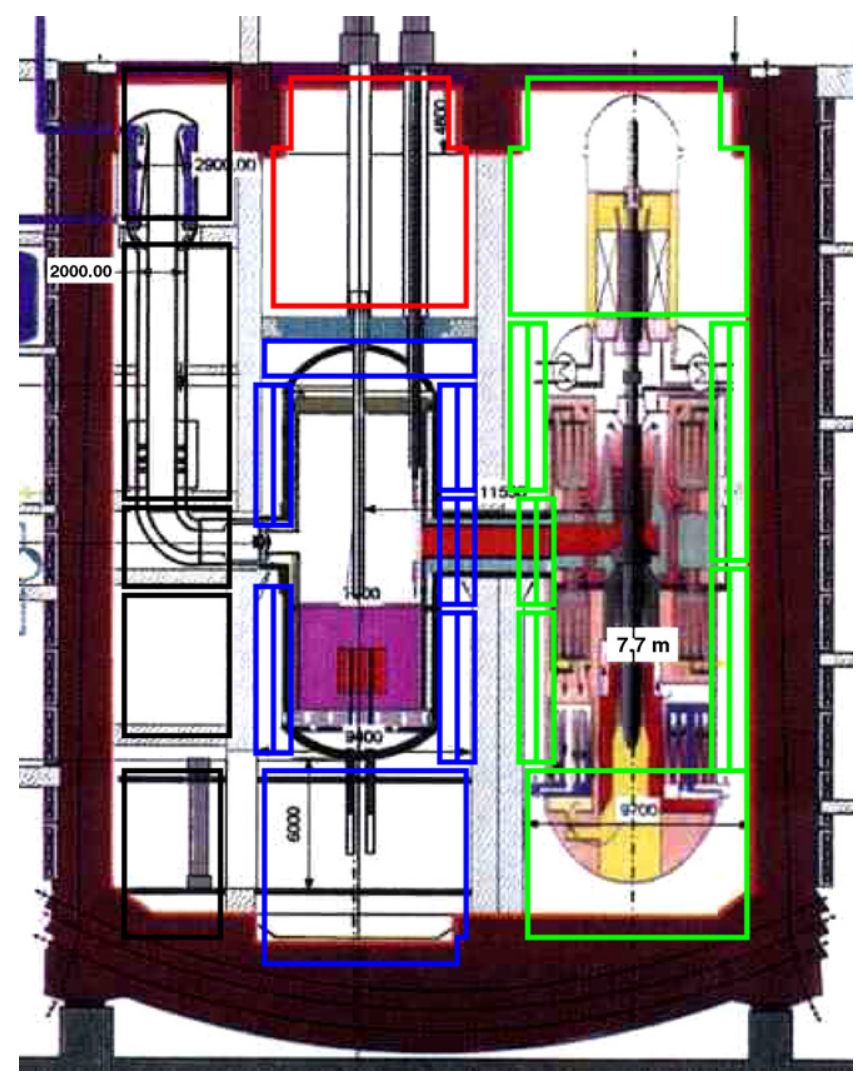

Fig. 2. GFR $600 \mathrm{MW}$-Proposed nodalization: front view.

Detailed distributions of the different walls between the 45 compartments are not reported in this article but this gives finally 118 walls. Connections between the different compartments are modeled by atmospheric junctions. In the proposed nodalization two situations may be identified. The first refers to a virtual nodalization of an open volume such as the reactor cavity or

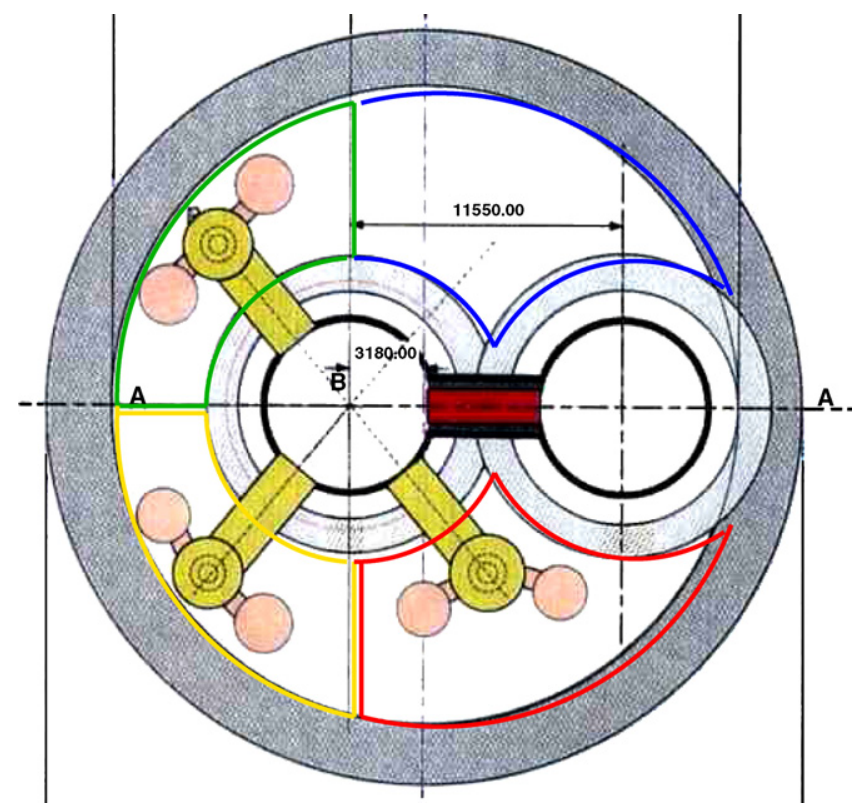

Fig. 3. GFR $600 \mathrm{MW}$-Proposed nodalization: upper view. the power conversion system compartment. For these, all the possible connections have been taken into account and the junction surface is taken as the real open surface, the length as the distance between the center of each compartment and the friction coefficient as 0.5 in vertical directions and 1.0 in horizontal directions. These numbers have been determined during verification processes (NUPEC M2-2 test and also MISTRA tests (Studer and Dabbene, 2003)). The second situation refers to real openings between compartments: doors, gratings in floors, holes for pipes, .... Regarding this latter point, the proposed design is not sufficient to characterize such geometrical details. So, it has been assumed that a limited number of connections exists between the different compartments and compared to French PWR containment a more confined geometry is adopted. Finally, 90 atmospheric junctions are used for the flow pattern nodalization.

\subsection{ARCTURUS/CATHARE depressurization scenario}

The fast depressurization of the core vessel occurring after a LOCA in a GCR study is a complex problem. Indeed, complex shock structures traveling and reflecting on the external containment may occur, threatening the integrity of the reactor systems. Detailed CFD simulations are needed for such analysis and this has been performed using compressible flow models of the ARCTURUS code for the safety evaluation of high pressure experimental loops. Here, we describe and use a simplified model to determine whether the average increase of pressure and temperature can threaten the integrity of the containment. The selected scenario corresponds to a small break LOCA ( 1 in. equivalent diameter) cumulated with station blackout. This depressurization accident scenario has been computed with the system code CATHARE (Dumaz et al., 2005) using constant conditions for the containment (pure helium at 10 bar total pressure). The main hypothesis regarding the accident scenario are the following:

- $2.5 \mathrm{~cm}$ small break LOCA in the cross-duct cumulated with station black-out.

- Safety core/turbine by-pass valve is in operation.

- Natural convection loop with a helium/CO2 heat exchanger (HEX) which comes into operation when the turbine velocity goes to zero.

- Inertia of the turbomachinary is taken into account and so, 10 bar of back-up pressure are estimated to be sufficient for residual heat removal by natural convection (preliminary study).

The main time schedule of the depressurization accident is:

- $t_{0}$ : reactor shut-down;

- $t_{0}+10 \mathrm{~s}$ : start of reduction of PCS rotation velocity;

- $t_{0}+54 \mathrm{~s}$ : stop of the PCS rotation;

- $t_{0}+64 \mathrm{~s}: \mathrm{He} / \mathrm{CO}_{2} \mathrm{HEX}$ in operation;

- $t_{0}+6180 \mathrm{~s}$ : equilibrium $P_{\text {vessel }}=10$ bar. 


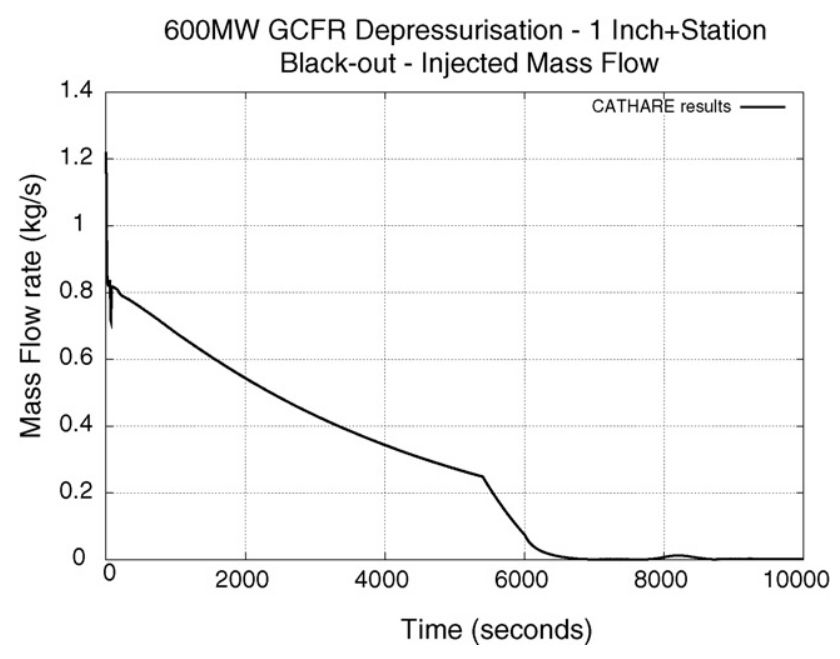

Fig. 4. GFR $600 \mathrm{MW}$ - Injected mass flow rate: CATHARE result of 1 in. break scenario.

600MW GCFR Depressurisation - 1 Inch+Station Black-out - Injected Enthalpy

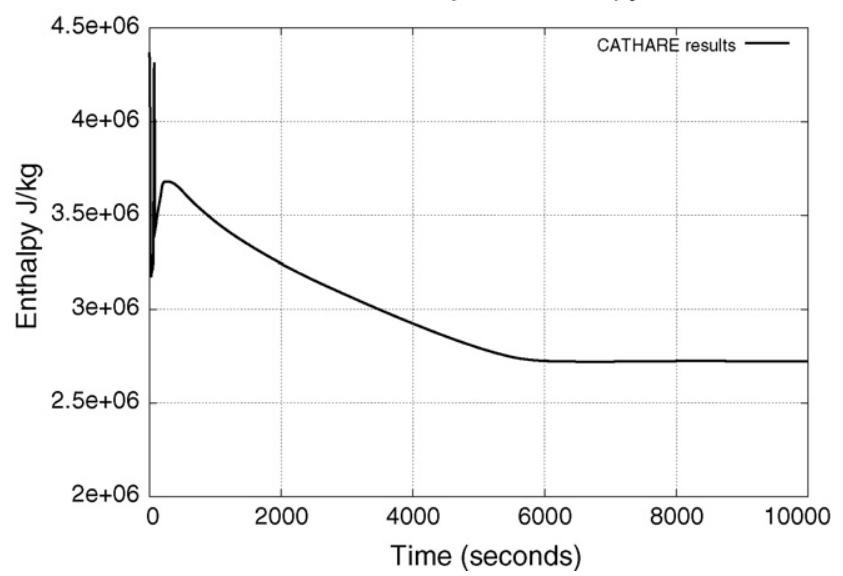

Fig. 5. GFR $600 \mathrm{MW}$-Injected enthalpy: CATHARE result of 1 in. break scenario.

and the mass and enthalpy at the break are plotted in Figs. 4 and 5. The injected energy during 10,000 s corresponds to about 9.9 GJ. The main containment thermal-hydraulic results are reported in Table 2 and Fig. 6. Due to slow transient (compared to large break LOCA), the calculated values are far from the adiabatic ones. Part of the energy is absorbed by the walls. Indeed, the maximum overpressure is computed at the end of the sonic phase and the maximum gas temperature in the break zone is reached earlier mainly due to the heat losses to the walls. Regarding gas mixing, gradients are maintained until the injected mass flow rate decreases (at about $6000 \mathrm{~s}$ ). Thermal

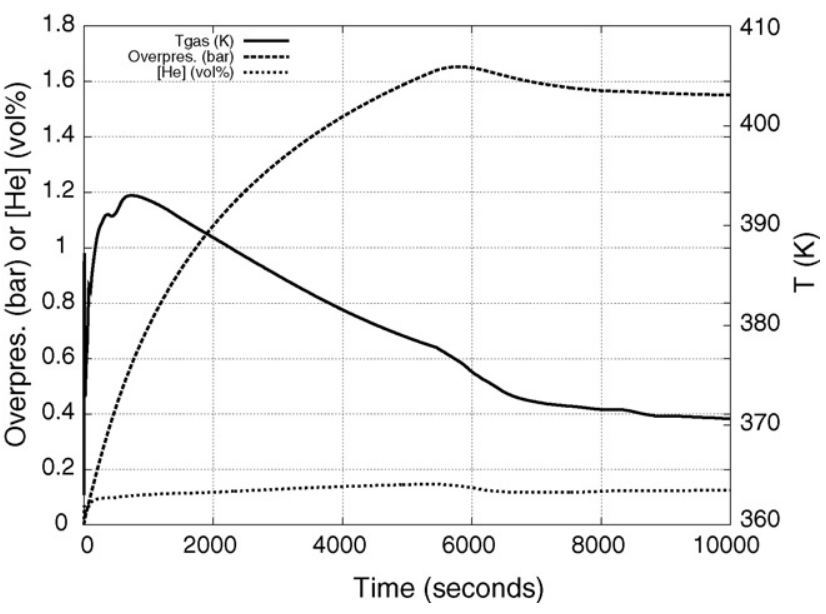

Fig. 6. GFR $600 \mathrm{MW}$-ARCTURUS containment results of 1 in. break scenario: Break zone overpressure, maximum temperature and helium volumetric concentration.

loads to the steel liner are very small for such scenario. Nevertheless, control volumes used in LP codes lead to homogeneisation and local effect may be more challenging (CFD simulation needed). There is also another important point in the model used in the present simulation: the heat transfer correlation used by the computer code (key parameter (Macnab, 1976)). We use a turbulent natural convection correlation along vertical plate $\left(N u=a(G r . P r)^{1 / 3}\right)$. Such correlation, free of length scale (due to $G r^{1 / 3}$ ) is suitable for a LP approach. Nevertheless, in a fast depressurization accident, forced convection (or at least mixed convection) occurs near the injection zone. Thus, the heat transfer is increased and available correlation introduces a Reynolds number (an additional length scale and velocity scale). Selection of such "user defined" parameters is not straightforward in a LP approach and this can be performed by several ways (height of the compartment, weighted velocities in the atmospheric junctions, ....). Indeed, a thorough validation process is needed to implement such extension and this has not been performed in the present study.

The next step will the feed-back of these containment thermal-hydraulic results on the CATHARE simulation (transient behavior of the back-up pressure, the gas temperature and the mixture composition). This last example concludes the containment thermal-hydraulic part. Pressure, gas temperature and concentration transient behaviors have been estimated for the guard containment. These results will be used first to check the possible modification of the in-vessel transient (onset of natural convection, possible air ingress, ...) and secondly to evaluate the structural behavior of the containment.

Table 2

GFR 600 MW - Summary of the thermal-hydraulics results for 1 in. break LOCA cumulated with station black-out (maximum overpressure and gaseous temperature, temperature and helium concentration levels in the injection zone after the equilibrium of pressure between containment and reactor vessel and steel liner maximum temperature increase)

\begin{tabular}{llllll}
\hline Case & $\Delta P_{\max }($ bar $)$ & $T_{\max }(\mathrm{K})$ & $T_{\text {rel. } t>t_{\text {eq }}}(\mathrm{K})$ & {$[\mathrm{He}]_{\text {rel. } t>t_{\text {eq }}}($ vol\% $)$} & $\leq T_{\text {max }- \text { WRH39 }}(\mathrm{K})$ \\
\hline 1 in. break & 1.7 & 393 & $\leq 375$ & $\leq 13$ & $4(5000 \mathrm{~s})$ \\
\hline
\end{tabular}




\section{GCR in-vessel thermal-hydraulics}

\subsection{Objectives}

This section is dedicated to in-vessel thermal hydraulics studies with ARCTURUS/CAST3M code for both HTR and GFR reactors. Different thermal hydraulic models are available in the code including 3D thermal/1D hydraulic and 3D equivalent porous media formulation. After a short description of these two formulations, a cross-comparison is detailed on a simplified test case, a single heated channel under forced convection (GFR fuel assembly). Then, some recent results obtained with the equivalent porous media formulation at the reactor scale are reported (HTR-10 thermal hydraulics benchmark).

\subsection{ARCTURUS models description}

\subsubsection{Equivalent porous media formulation}

The asymptotic low Mach number flow model using equivalent porous media formulation developed for the ARCTURUS code solves the following set of equations: let us first introduce the porous media velocity

$\vec{u}_{\mathrm{D}}=\beta \vec{u}$

where $\beta$ represents the porosity (ratio of fluid volume to total volume) and $\vec{u}$ the velocity. The dynamic pressure $p^{\prime}(P(x, t)=$ $\left.P(t)+p^{\prime}(x, t)\right)$ is recovered from the velocity divergence constrain:

$\nabla \cdot \vec{u}_{\mathrm{D}}=-\frac{1}{\rho_{\mathrm{f}}}\left(\beta \frac{\partial \rho_{\mathrm{f}}}{\partial t}+\vec{u}_{\mathrm{D}} \cdot \vec{\nabla} \rho_{\mathrm{f}}\right)$

where $\rho_{\mathrm{f}}$ represents the fluid density. The velocity field $\vec{u}_{\mathrm{D}}$ is obtained from the momentum equation:

$\frac{\rho_{\mathrm{f}}}{\beta} \frac{\partial \vec{u}_{\mathrm{D}}}{\partial t}+\frac{\rho_{\mathrm{f}}}{\beta^{2}} \vec{u}_{\mathrm{D}} \cdot \vec{\nabla} \vec{u}_{\mathrm{D}}=\vec{F}+\rho_{\mathrm{f}} \vec{g}-\vec{\nabla} p^{\prime}+\frac{\mu+\mu_{\mathrm{T}}}{\beta} \vec{\Delta}_{\mathrm{D}}$

where $\vec{F}$ represents the frictional pressure loss, $\vec{g}$ the gravity and $\mu_{\mathrm{T}}$ the turbulent viscosity. The fluid temperature $T_{\mathrm{f}}$ comes from the fluid energy balance:

$\rho_{\mathrm{f}} C p_{\mathrm{f}} \beta \frac{\partial T_{\mathrm{f}}}{\partial t}+\rho_{\mathrm{f}} C p_{\mathrm{f}} \vec{u}_{\mathrm{D}} \cdot \vec{\nabla} T_{\mathrm{f}}=\beta \nabla \cdot\left(\lambda+\lambda_{\mathrm{T}}\right) \vec{\nabla} T_{\mathrm{f}}+W_{\mathrm{fs}}$

where $\lambda_{\mathrm{T}}$ represents the turbulent heat conductivity and $W_{\mathrm{fs}}$ the heat flux inside the porous media determined by correlations for the heat exchange coefficient. Then, the solid temperature $T_{\mathrm{S}}$ is expressed from the solid energy balance:

$(1-\beta) \rho_{\mathrm{s}} C p_{\mathrm{s}} \frac{\partial T_{\mathrm{s}}}{\partial t}=\lambda_{\text {eq }} \Delta T_{\mathrm{s}}-W_{\mathrm{fs}}+\Phi_{\mathrm{rad}}+\Phi_{\text {neutro }}$

where $\lambda_{\text {eq }}$ represents the equivalent thermal conductivity of the homogenized porous media, $\Phi_{\text {rad }}$ the power exchanged by thermal radiation and $\Phi_{\text {neutro }}$ the nuclear power. Finally, the equation of state is used with constant thermodynamic pressure (steadystate) to recover the fluid density $\rho_{\mathrm{f}}$ :

$\rho_{\mathrm{f}} T_{\mathrm{f}}=$ constant
The spatial discretization uses finite elements (Q2P1: quadratic for velocity and linear for pressure) and the numerical method uses semi implicit incremental projection method (Studer and Dabbene, 2003). The linear system is solved by using classical iterative methods. Thermal radiation is based on classical grey surfaces emissivity in enclosures methods available in the CAST3M code.

\subsection{2. $3 D$ thermal/1D hydraulic formulation}

A simplified steady state model has been implemented in the CAST3M/ARCTURUS code in order to study the thermal behavior of a vertical fuel assembly under normal conditions or in case of accidental blocked channel. In this model, the thermal behavior is supposed to be 3D and the flow is assumed 1D. The thermal coupling between the both is performed via correlations. Thermal radiation and pressure losses are neglected in this geometry configuration. With the above assumptions, the system of equation reduces to:

- energy conservation in the solid part

$\nabla \cdot\left(-\lambda_{\mathrm{S}} \nabla T_{\mathrm{s}}\right)=W_{\mathrm{s}}$

where $\lambda_{\mathrm{S}}$ is the homogenized fuel heat conductivity, $T_{\mathrm{S}}$ the fuel temperature and $W_{\mathrm{s}}$ is the power generated in the reactor core.

- mass conservation in the fluid region

$$
S_{\text {channel }} \frac{\partial \rho_{\mathrm{f}} w}{\partial z}=0
$$

where $z$ is the vertical coordinate, $\rho_{\mathrm{f}}$ the coolant density, $w$ the coolant vertical velocity and $S_{\text {channel }}$ is the fluid channel cross section.

- energy conservation in the fluid region

$$
S_{\text {channel }} \frac{\partial \rho_{\mathrm{f}} C p_{\mathrm{f}} w T_{\mathrm{f}}}{\partial z}=S_{\text {channel }} \frac{\partial}{\partial z}\left(\lambda_{\mathrm{f}} \frac{\partial T_{\mathrm{f}}}{\partial z}\right)+W_{\mathrm{f}}
$$

where $C p_{\mathrm{f}}$ is the coolant heat capacity, $T_{\mathrm{f}}$ the coolant temperature, $\lambda_{\mathrm{f}}$ the coolant heat conductivity and $W_{\mathrm{f}}$ the volumetric heat source described below.

Regarding boundary conditions, the coolant temperature $\left(T_{\mathrm{f}}\right)$ and the coolant mass flow rate $\left(\rho_{\mathrm{f}} w\right)$ at the inlet are imposed, zero flux conditions are supposed on the outer solid surface and for the surface between coolant and solid

$-\lambda_{\mathrm{s}} \frac{\partial T_{\mathrm{s}}}{\partial n}=h\left(T_{\mathrm{s}}-T_{\mathrm{f}}\right)$

where $n$ is the normal vector and $h$ a heat exchange coefficient described below. The coolant properties including $\rho_{\mathrm{f}}$ are supposed to be temperature-dependent (Melese and Katz, 1984).

\subsubsection{Coupling between fuel and coolant channels}

From the Colburn correlation,

$N u=0.023 \operatorname{Re}^{0.8} \operatorname{Pr}^{1 / 3}$ 
Table 3

Main characteristics of the GFR 600 MW "CerCer performant"

Thermal power (MW)

Power density $\left(\mathrm{MW} / \mathrm{m}^{3}\right)$

600

Diameter of the helium chan 103

Porosity $(\%)$

Height of the reactor core $(\mathrm{m})$

Diameter of the reactor core $(\mathrm{m})$

Injection helium mass flow rate $(\mathrm{kg} / \mathrm{s})$

Inlet helium temperature $\left({ }^{\circ} \mathrm{C}\right)$

$\operatorname{Pr}=\frac{\mu_{\mathrm{f}} C p_{\mathrm{f}}}{\lambda_{\mathrm{f}}}$

where the non-dimensional numbers $(\mathrm{N} u$ Nusselt number, $R e$ Reynolds number and $\operatorname{Pr}$ Prandtl number) are:

$N u=\frac{h d_{\mathrm{H}}}{\lambda_{\mathrm{f}}}$

$R e=\frac{\rho_{\mathrm{f}} w d_{\mathrm{H}}}{\mu_{\mathrm{f}}}$

these numbers are evaluated at a mean temperature:

$T_{\mathrm{m}}=\frac{T_{\mathrm{s}}+T_{\mathrm{f}}}{2}$

one can deduce the heat exchange coefficient $h$. Then, the volumetric heat source $W_{\mathrm{f}}$ can easily be expressed from the surface integration of (14) at a given elevation $z_{0}$.

\subsection{Elementary test case: GFR fuel assembly under normal conditions}

Comparison of the two previous models on a simplified test case is performed in this section. The test case correspond to GFR prismatic fuel element with the main characteristics defined in Table 3. Additional hypotheses are assumed:

- a cosine shape of the power density is selected with the same axial peaking factor (1.5),

- no irradiation effect has been taken into account on the thermal conductivity of the fuel element,

- helium is supposed to behave as a perfect gas.

The maximum temperatures are compared in Table 4. A difference of about $90^{\circ} \mathrm{C}$ is computed between the two models. If one compares the homogenized temperature of the $1 \mathrm{D}-3 \mathrm{D}$

Table 4

Verification of the proposed model

\begin{tabular}{llc}
\hline Characteristic & 1D-3D model & 2D axis model \\
\hline Fuel maximum temperature $\left({ }^{\circ} \mathrm{C}\right)$ & 1161.9 & 1072.9 \\
Fluid maximum temperature $\left({ }^{\circ} \mathrm{C}\right)$ & 848.8 & 849.6 \\
Nusselt number $(\min / \max )$ & $135-170$ & $140-175$ \\
Heat exchange coefficient $(\min / \max )$ & $3086-3276$ & $3072-3249$ \\
$\quad\left(\mathrm{~W} / \mathrm{m}^{2} / \mathrm{K}\right)$ & & \\
\hline
\end{tabular}
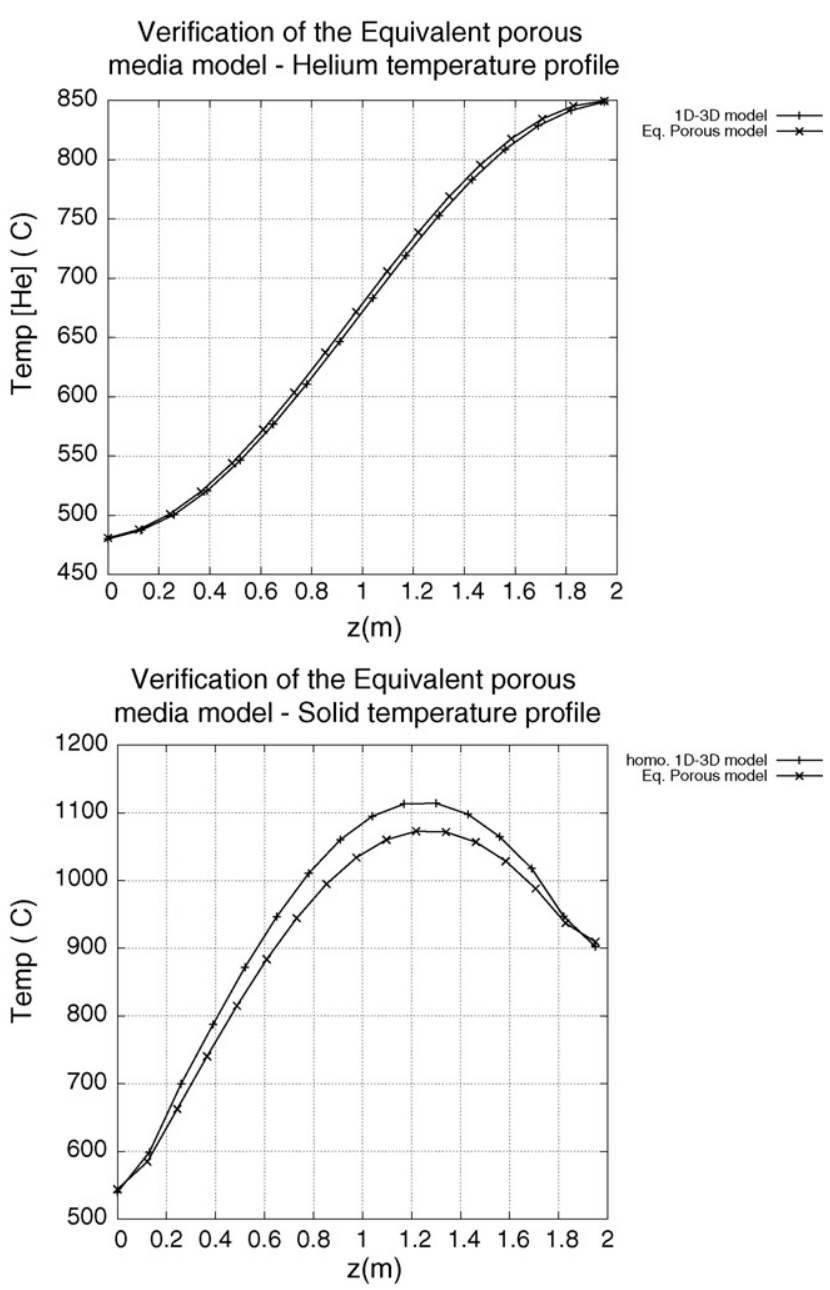

Verification of the Equivalent

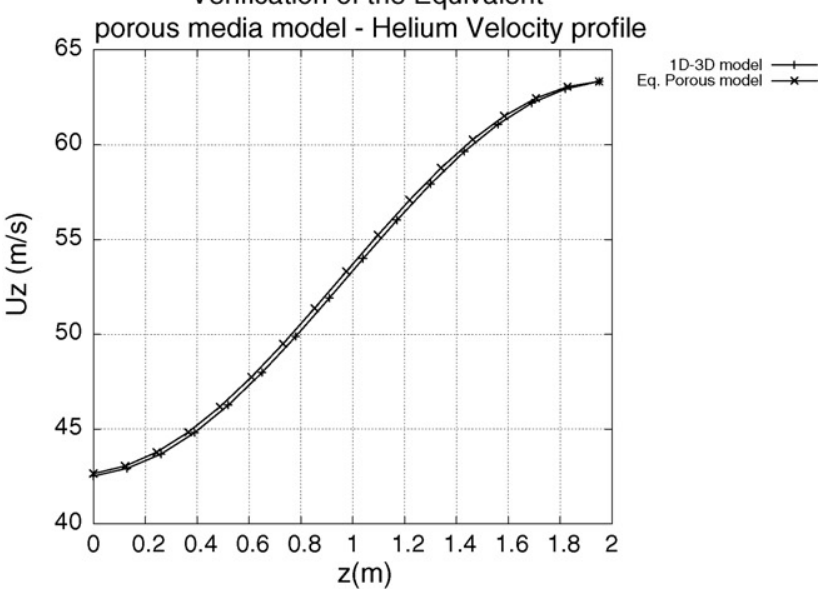

Fig. 7. Comparison 1D-3D model and Equivalent Porous media modelvertical profiles (Top: helium temperature, Middle: homogenized fuel temperature, Bottom: fluid velocity.

model (surface homogenization at each axial level), the difference decreases to about $40^{\circ} \mathrm{C}$ (Fig. 7). The main reason for that difference is the non azimuthal symmetry of the 1D-3D model (Fig. 8). The maximum fuel temperature is located at the same location for the both models. The computed pressure drop through the reactor core is about $0.15 \mathrm{bar}$ ( $1.95 \mathrm{~m}$ in height) in 


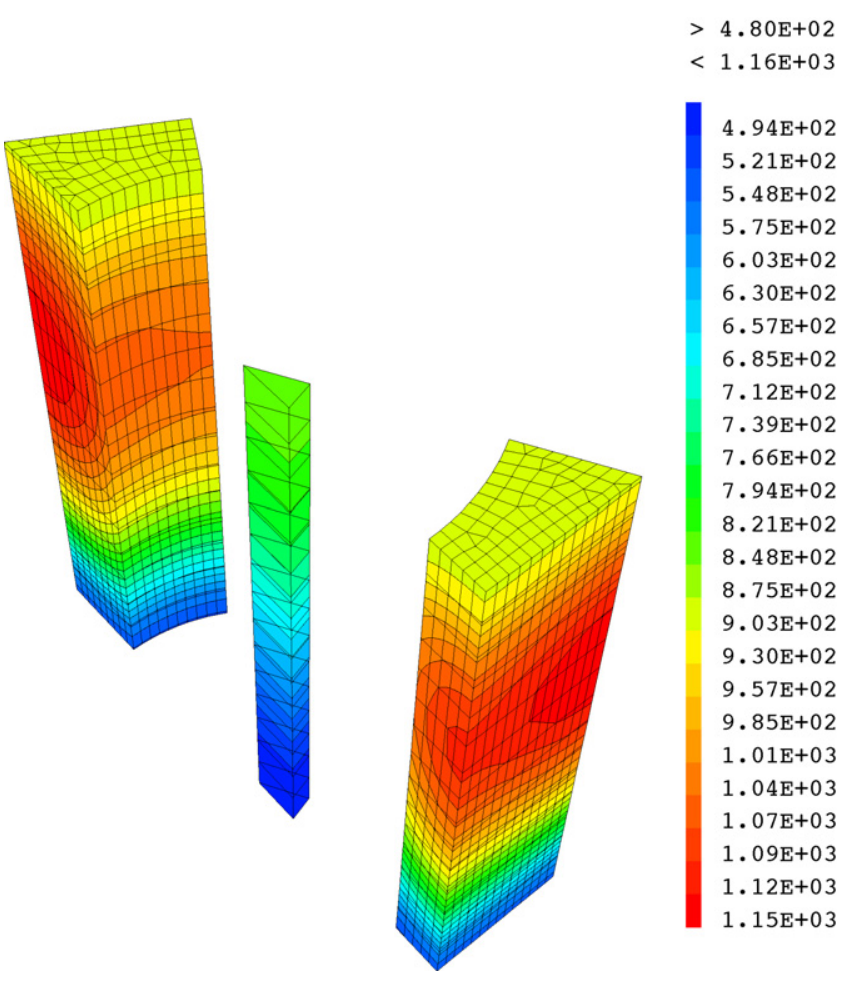

Fig. 8. Verification of proposed model-3D temperature field: Solid Temperature between 480 and $1162{ }^{\circ} \mathrm{C}(1 \mathrm{D}-3 \mathrm{D}$ model).

the equivalent porous media model and this is comparable to the value estimated by classical correlations. By using the friction coefficient correlation (Blasius type)

$f=0.316 R e^{-0.25}$

the pressure drops can be estimated by a simplified momentum balance (inlet and outlet pressure drops are neglected):

$$
\begin{aligned}
p_{\text {out }}-p_{\text {in }}= & {\left[\bar{\rho}_{\mathrm{f}}-\rho_{\mathrm{f}, \mathrm{m}}\right] g L-\left[\rho_{\mathrm{f}, \text { out }} u_{\text {out }}^{2}-\rho_{\mathrm{f}, \mathrm{in}} u_{\text {in }}^{2}\right] } \\
& -\frac{1}{2} \frac{\rho_{\mathrm{f}, \mathrm{m}} f_{\mathrm{m}} L}{d_{\mathrm{H}}} u_{\mathrm{m}}^{2}
\end{aligned}
$$

where the subscript 'in' refers to the inlet conditions, 'out' to the outlet conditions, $\rho_{\mathrm{f}, \mathrm{m}}$ corresponds to the mean value of the density in the reactor core and $\bar{\rho}_{\mathrm{f}}$ to the external conditions (it is assumed regarding the plenum volumes that the external condition is composed of $80 \%$ of the hot helium and $20 \%$ of the cold helium). This gives the following results for the different terms of the pressure difference:

- gravity term: $6 \mathrm{~Pa}$,

- inertia term: $3976 \mathrm{~Pa}$,

- friction term: 11,669 Pa.

As expected, the friction term represents the main part of the pressure difference under forced convection conditions. So, the total pressure difference is about 0.156 bar. Finally, we can conclude that our equivalent porous media gives accurate results and has been checked under forced convection conditions. Verification of this model is the subject of the next section.

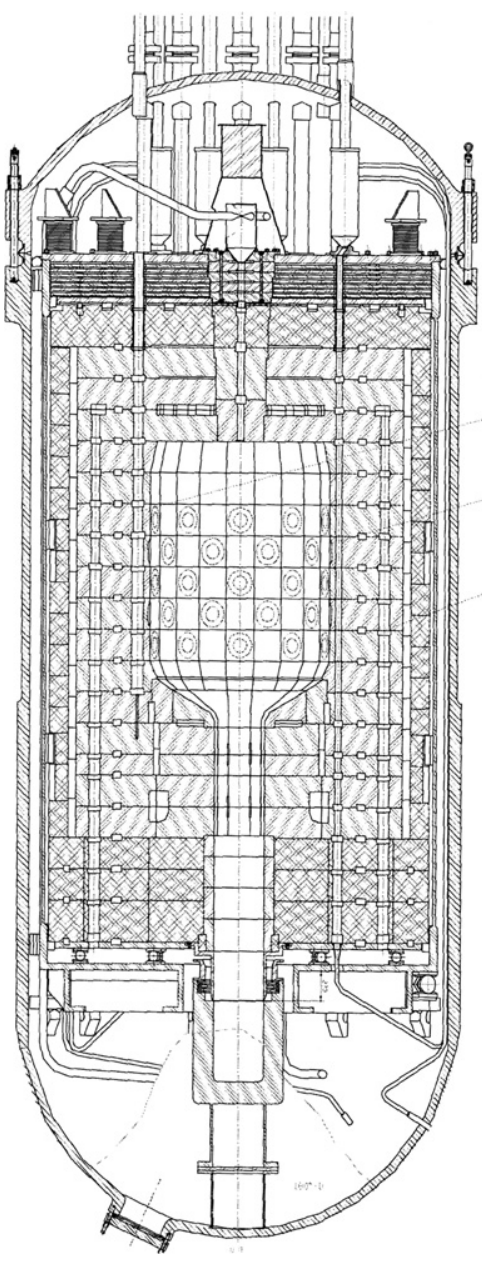

Fig. 9. HTR-10-Vessel view.

\subsection{HTR-10 benchmark exercise}

HTR-10 is a pebble bed High Temperature gas cooled reactor designed, constructed and operated by the Institute of Nuclear Energy Technology (INET) in China. Full power operation with a core outlet temperature at $700{ }^{\circ} \mathrm{C}$ was achieved in January 2003. This reactor operates with a primary helium pressure of about $3 \mathrm{MPa}$ and a core inlet temperature of $250^{\circ} \mathrm{C}$. The benchmark proposed within the IAEA/CRP5 framework (Dong and Sun, 2003) is devoted to steady state temperature distribution inside the reactor vessel for Full Power Initial Core (FPIC). It has been proposed both for code-to-code and for code-toexperiment benchmarking. Thermocouples have been installed in the reactor cavity to provide the experimental results. CEA contributes to this benchmark exercise with the ARCTURUS CFD code (equivalent porous media formulation). A vertical cross-section of the HTR-10 Reactor Pressure Vessel (RPV) is described in depth and plotted in Fig. 9. The active core is cylinder-shaped and cone-shaped at the bottom to unload fuel elements. It is surrounded by graphite reflectors categorized as top, side and bottom reflectors. The active core and the reflectors are enclosed in a core vessel radially and upper and lower core support plates axially. Stagnant helium between this core vessel and the reactor pressure vessel acts as insulation and most 


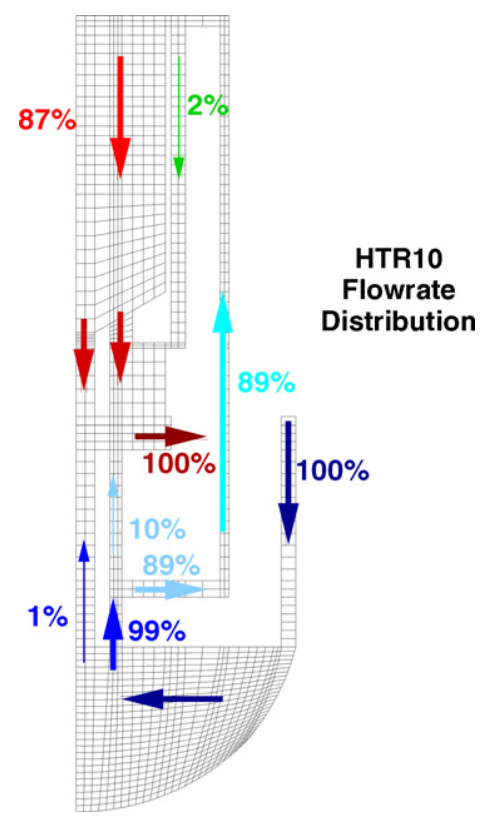

Fig. 10. HTR-10—-Specified mass flow-rate distribution.

of the heat is transfered by thermal radiation. After entering the RPV, the cold helium flows downwards through the annular gap between the core vessel and the RPV. Then it changes its flow direction to flow upwards. A small part of this cold helium goes through the cone-shaped discharging tube to cool the fuel elements and after merges with the hot helium. The major part of helium goes around the core support structures and enters into the cold helium channels in the side reflector. At the top of this reflector, cold helium is collected in the upper plenum and then for a second time, it changes its flow direction. Part of this helium goes through the control rods channels and is collected in a small plenum above. The main stream of
HTR10 Benchmark - CAST3M/ARCTURUS - Profiles

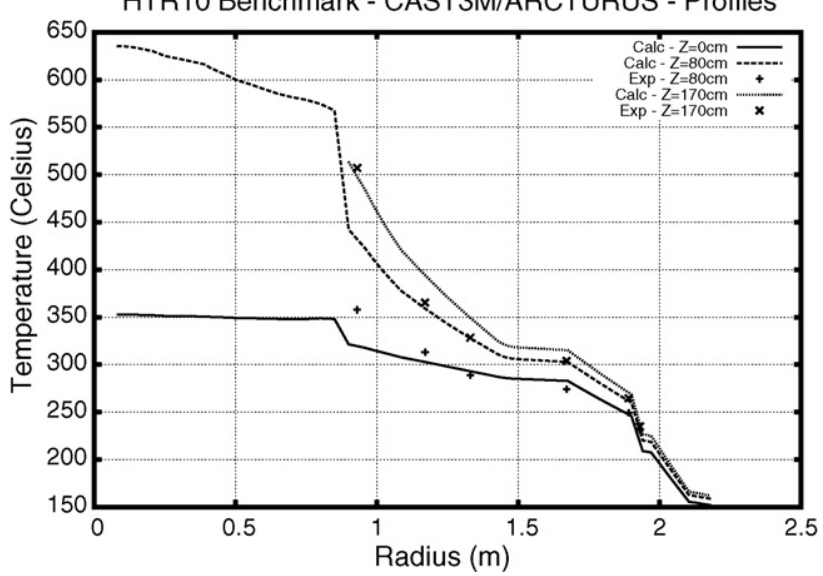

Fig. 11. HTR-10-CAST3M/ARCTURUS results: radial temperature profiles (in the solid region).

helium flows through the active core and is collected in the lower hot plenum (Fig. 10). Correlations (friction pressure drops, heat transfer in the pebble bed, ...), delivered nuclear power distribution and material properties (solids and helium coolant) have been provided in the specification document (Dong and Sun, 2003). Constitutive relations are very important but are not discussed in the present article because there have been provided in the benchmark specification document. Illustrations of the ARCTURUS results compared to the provided experimental results (Dong and Sun, 2004) are given below. Interpretation of the differences are still under discussion and so, only a few comments are reported. Three radial solid temperature profiles have been selected for comparison at $Z=0 \mathrm{~cm}, Z=80 \mathrm{~cm}$ and $Z=170 \mathrm{~cm}$ in Fig. 11 (the reference point $(0,0)$ is located in the upper center of the pebble bed). First, the computed results do not start at $0.0 \mathrm{~m}$ radius because of symmetry axis translation needed by quadratic finite element discretization. Second, the

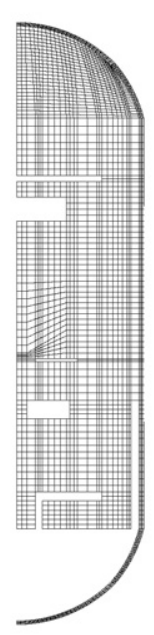

Solid Grid 12195 nodes
CAST3M/ARCTURUS HTR10 Grids
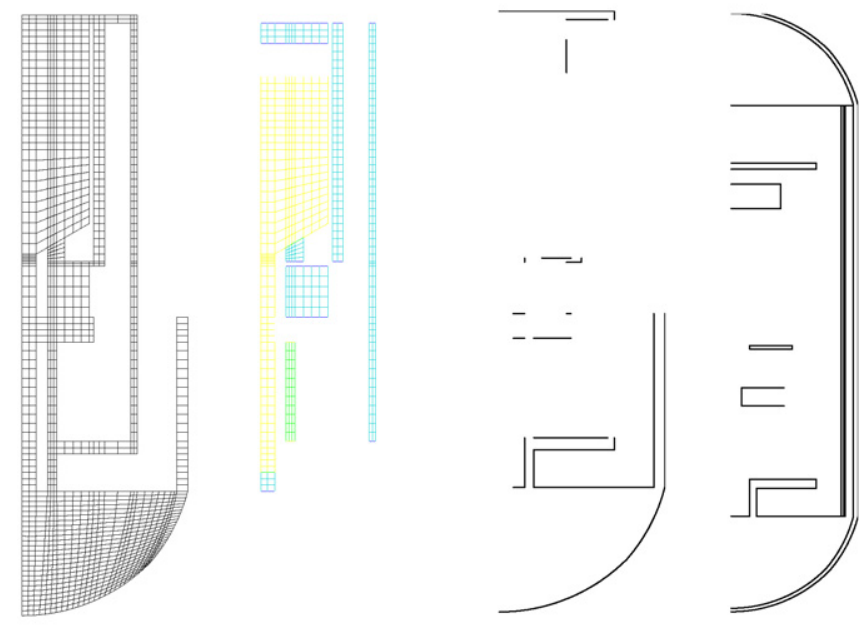

Fluid Grid 6095 nodes
Porous Media Grid 2644 nodes
Convective heat transfer
Radiative heat transfer 753 elements

Fig. 12. HTR-10—CAST3M/ARCTURUS mesh description. 
Table 5

HTR-10 benchmark: hot helium plenum temperature near the outlet ( $T_{\mathrm{sol}}$ : solid temperature, $T_{\mathrm{flu}}$ : fluid temperature, $\mathrm{d} T / \mathrm{d} r$ : radial solid temperature gradient and $\mathrm{d} T / \mathrm{d} z$ axial solid temperature gradient)

\begin{tabular}{llllllrl}
\hline $\mathrm{Nb}$. & $R(\mathrm{~cm})$ & $Z(\mathrm{~cm})$ & Calculated $T_{\text {sol }}\left({ }^{\circ} \mathrm{C}\right)$ & Calculated $T_{\text {flu }}\left({ }^{\circ} \mathrm{C}\right)$ & $\mathrm{d} T / \mathrm{d} r\left({ }^{\circ} \mathrm{C} / \mathrm{m}\right)$ & $\mathrm{d} T / \mathrm{d} z\left({ }^{\circ} \mathrm{C} / \mathrm{m}\right)$ & Experimental $T\left({ }^{\circ} \mathrm{C}\right)$ \\
\hline 14 & 40 & 234 & 783 & 785 & -159 & -8 & 800.2 \\
15 & 60 & 234 & 740 & 742 & -220 & -55 & 763.1 \\
\hline
\end{tabular}

computed profile at $Z=170 \mathrm{~cm}$ is not reported in the active core due to grid deformation (see Fig. 12). The comparison with the experimental results shows a rather poor comparison especially in the middle core axial level. Nevertheless, it seems that the slopes are rather well predicted (correctly computed conduction fluxes). One important reason for that deviation could be the thermal effect of the by-pass through the control rods. In this region, a by-pass of $2 \%$ of the total mass flow rate creates a laminar flow through the control rods channels and in the computation, the heat extracted by this convective transfer may be perhaps too low compared to the reactor case. In the hot helium plenum (Table 5), the calculated temperatures are lower than the measured ones (about $20^{\circ} \mathrm{C}$ ) and the radial difference is adequate. One has to remember that the computed values correspond to homogenized values of the solid temperature and no reconstruction is proposed in the present study to recover the solid temperature. A $2 \mathrm{D}$ view of the computed solid temperature and velocity fields in the core region is given in Fig. 13. This benchmark exercise has demonstrated the capabilities of CAST3M/ARCTURUS code to simulate steady state temperature fields including complex convective, conductive and radiative heat transfers. Some dis-

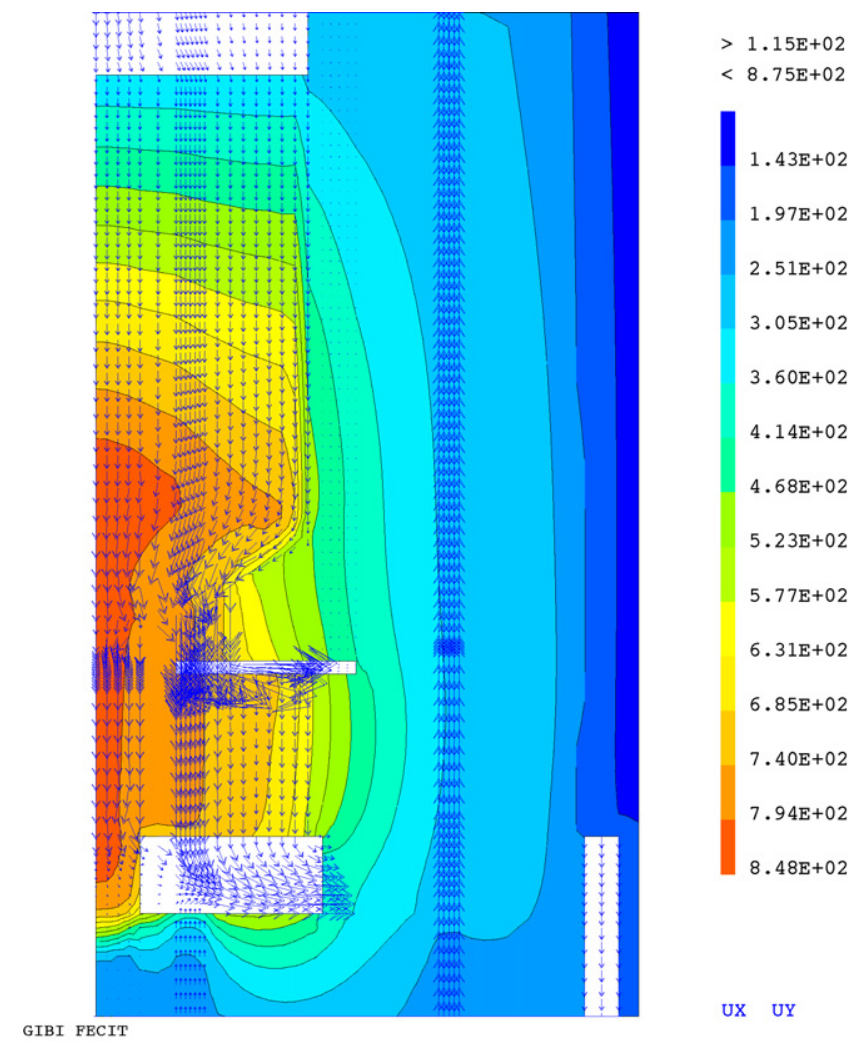

Fig. 13. HTR-10—CAST3M/ARCTURUS: solid temperature and Velocity field (zoom). crepancies between the calculated and the measured values still exist especially where convective heat transfer is important (bypass regions). Some adjustment may be done after discussions of the present results with the experimental team.

\section{Coupling between thermal-hydraulics and neutronics in HTR}

One of the principal objectives of CEA's R\&D on HTR is the development of a global simulation system. This model will be used for the design of different reactor configurations, the evaluation of their performances and finally the optimization of the different design parameters. Coupling thermal-hydraulic with the neutronic modeling allows to determine the impact of the temperature feed-back on the neutronic parameters such as cross-sections, power distribution but also the temperature coefficient (Doppler, moderator), critical position of control rods (Yadigaroglu et al., 2003; Rademer et al., 2004; Reitsma et al., 2004). A preliminary version of neutronic and thermal-hydraulic coupling system, based on a generic thermal-hydraulic model (Studer and Coulon, 2003), and v0 neutronic calculation scheme (Limaiem et al., 2005) was developed in the past. In the next paragraph we present the new coupling system. This new simulation system is based on the one hand on an improved thermal-hydraulic model (described in the previous paragraphs) and on the other hand on the v2 neutronic calculation scheme. In this section, first, the new coupling system is detailed. Then, some results of the sensitivity study are discussed. And finally an example of coupling is detailed.

\subsection{Coupling system architecture}

The architecture of the coupling system is built on the combination of two computer codes: CRONOS2 for the core neutronic calculation and CAST3M/ARCTURUS for the core thermal-hydraulics calculation (Fig. 14). Linux PIPE system files supervise the data exchange between the different calculations. The coupling system is very complex. In fact, it depends on many numerical and physical parameters (Limaiem et al., 2005). In order to evaluate the importance of each parameter and to reduce the system dependency on those parameters, we carry out a sensitivity study to evaluate the weight of each parameter and the accuracy of system.

\subsection{Coupling system parameter sensitivity study}

The sensitivity study involves many numerical and physical parameters. An exhaustive review of the system variables has been established. Only the main parameters are preserved for 


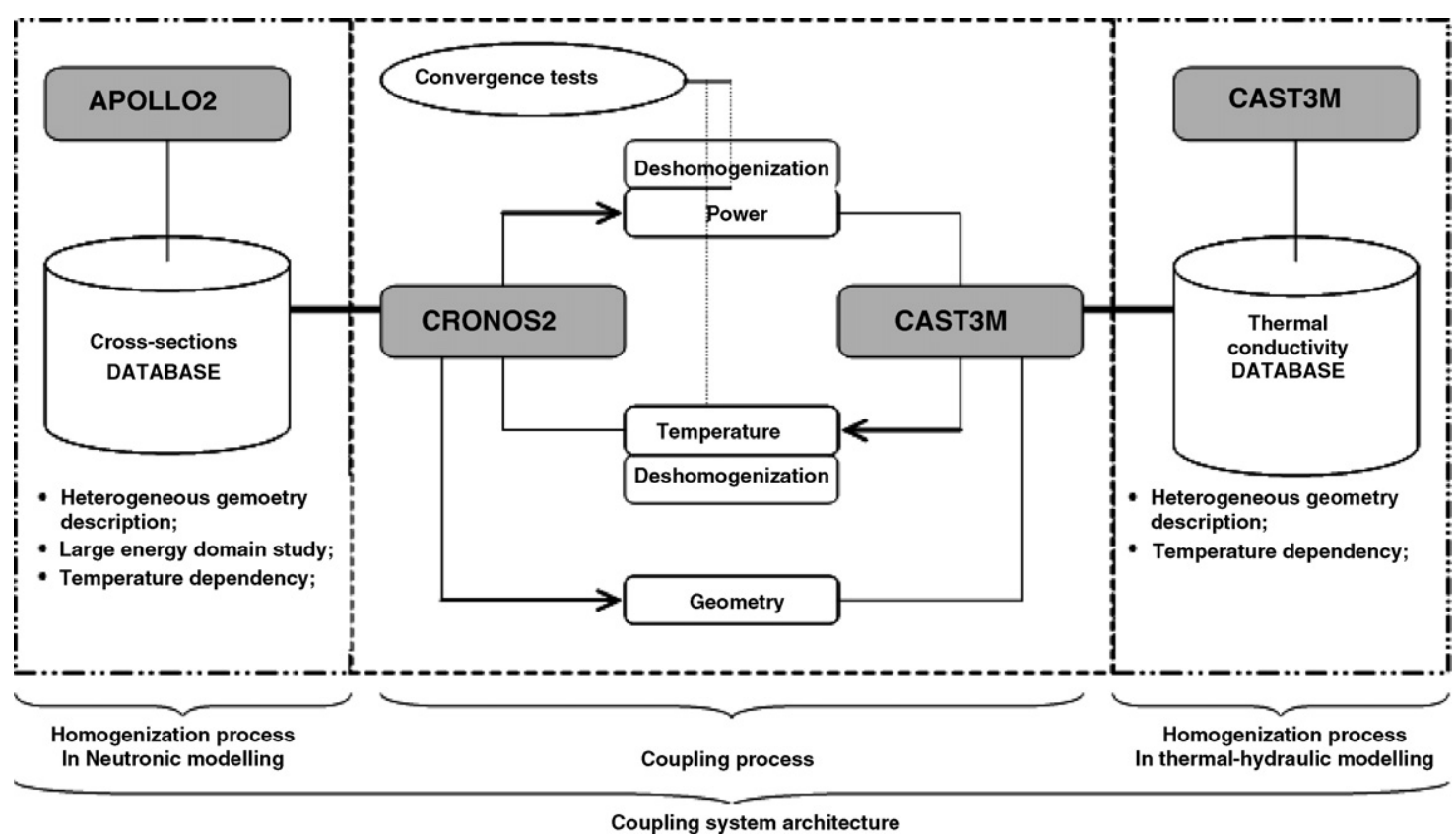

Fig. 14. Schematic description of the thermal-hydraulic/neutronic coupling architecture.

the sensitivity study. The selected parameters are the following:

- radial and axial meshing in the thermal-hydraulics calculation modeling,

- axial meshing in the neutronic calculation modeling,

- number of power and temperature values exchanged between the neutronic and the thermal-hydraulics calculation,

- the number of depletion regions in the fuel element,

- the homogeneous thermal conductivity in the coupling system,

- helium by-pass repartition,

- the equivalent hydraulic diameter of the inter-assembly helium gap,

- accuracy in the calculation of neutron flux during the coupling calculation,

- fuel burn-up distribution in the core.
Results dealing only with radial and axial thermal-hydraulic meshing are detailed below. The geometry used for this study relates to an annular prismatic blocks core type. For each sensitivity study a reference configuration is defined. It allows comparison between different test cases. We choose this method since at present time there are no available thermal and neutronic experimental results for HTR reactor. A reference case is characterized by a fine meshing and optimal set of input parameters for both neutronic and thermal-hydraulic calculations.

\subsubsection{Radial meshing study for the thermal-hydraulics modeling}

We define a reference thermal-hydraulics radial meshing described in Fig. 15. The same radial meshing as in the neutronic modeling is used (Limaiem et al., 2005). Then, we compare these results to a coarse grid configuration described in Fig. 16.
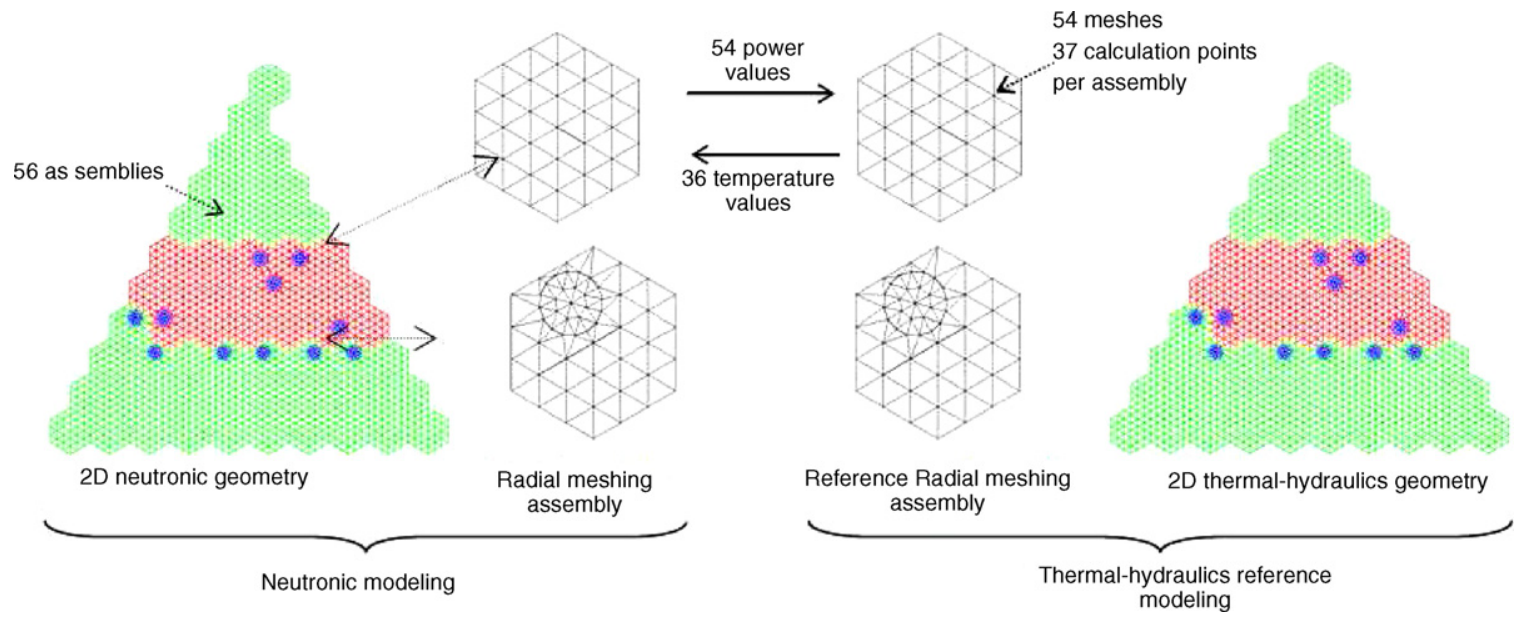

Fig. 15. Reference meshing for the radial meshing sensitivity study. 


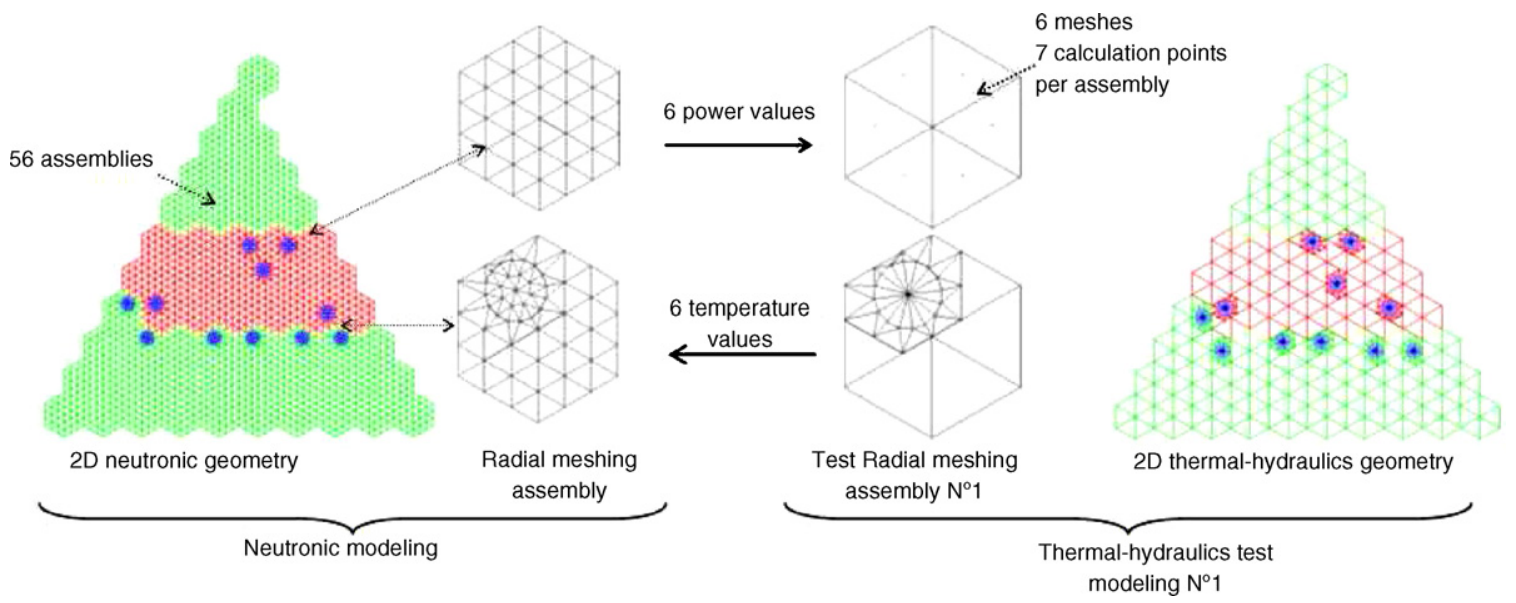

Fig. 16. Different test configurations investigated in the sensitivity study.

In the reference configuration, there are 36 meshes in the standard fuel and reflector assemblies (61 in the control assemblies). The number of meshes in the test configuration is reduced to 6 in the standard fuel and reflector assemblies (32 in the control assemblies). On the one hand, for the reference case, we exchange 54 power values and 36 temperatures per assembly. On the other hand, we exchange only 6 power values and 6 temperature values in the test configuration. The number of temperature values exchanged between the neutronic and the thermal-hydraulics calculation is directly related to the number of depletion regions defined in the neutronic modeling. The temperature and the power values exchanged between codes are calculated by homogenization procedures. The comparison between reference and test case is made on both detailed and integral neutronic and thermal-hydraulics results of the coupling calculation such as:

- neutronic eigenvalue,

- $1 \mathrm{D} / 2 \mathrm{D} / 3 \mathrm{D}$ power and temperature distribution,

- power axial offset,

- energy distribution in the core.

For all coupling calculations made in the sensitivity study, all neutronic modeling parameters are fixed so we could evaluate properly the influence of the thermal-hydraulic meshing. The comparison of the 2D power and thermal distributions between the reference (fine mesh) and the test configuration (N1 - coarse mesh) shows variations under $1 \%$ of the power for $80 \%$ of the meshes in Fig. 17. For the 2D thermal distribution variations are under $2 \mathrm{~K}$ on $70 \%$ of the meshes in Fig. 17. For all the investigated test configurations, variations never exceed $3 \%$ of the power and $30 \mathrm{~K}$. These differences are located in regions characterized by an important power and temperature gradient (between fuel and reflector assemblies). If we only take into account the coupling calculation CPU time of each configuration, we could choose test configuration N1 of thermal-hydraulic meshing for the $3 \mathrm{D}$ calculation. Indeed, the reference configuration takes twice as much CPU time calculation of test configuration N1 (thermal-hydraulic part). Moreover, the dis- crepancies observed on the neutronic power are under $1 \%$ for $80 \%$ of the calculation meshes. This value of $1 \%$ is acceptable since we define this value as convergence criteria for the power distribution during the coupling calculation. In other words, variations less than $1 \%$ have no interest because the precision in the power distribution is $1 \%$. The temperature variation concerning the test configuration $\mathrm{N} 1$ is also acceptable since we are under $2 \mathrm{~K}$ on $70 \%$ of the meshes.

\subsubsection{Axial meshing study for the thermal-hydraulics modeling}

We use the same method as the one defined for the radial mesh. We select an axial meshing reference for thermal-hydraulics modeling in Fig. 18. Then we made comparison to coarser grid configurations in Fig. 19 (we present only one test case). All thermal-hydraulics configurations are coupled with a reference neutronic calculation modeling. The results of the comparison between the reference axial meshing and the meshing test configuration $\mathrm{N} 2$ shows differences in temperature that reaches $30 \mathrm{~K}$ in the fuel assemblies zone of the core in Fig. 20 (at each axial level, a 2D examination of the power and temperature field is performed). In the other part of the core temperature difference varies from $-15 \mathrm{~K}$ to $+15 \mathrm{~K}$. These temperature variations cause differences in the power distribution of 5\% in certain regions of the core. We demonstrate that the use of four axial calculation points per assembly in the thermal-hydraulics modeling reduces the temperature discrepancies to $5 \mathrm{~K}$. In this study, the differences on power distribution are under $2 \%$.

The radial and axial meshing study performed in the thermal-hydraulic modeling of the coupling system allows us to evaluate the impact of the meshing on the neutronic and thermal results of the coupling system. Thus, we define an optimal thermal-hydraulics model for the coupling system described as the following:

- 6 radial meshes for standard assemblies,

- 32 radial meshes for control assemblies,

- 5 axial meshes for standard and control assemblies, 

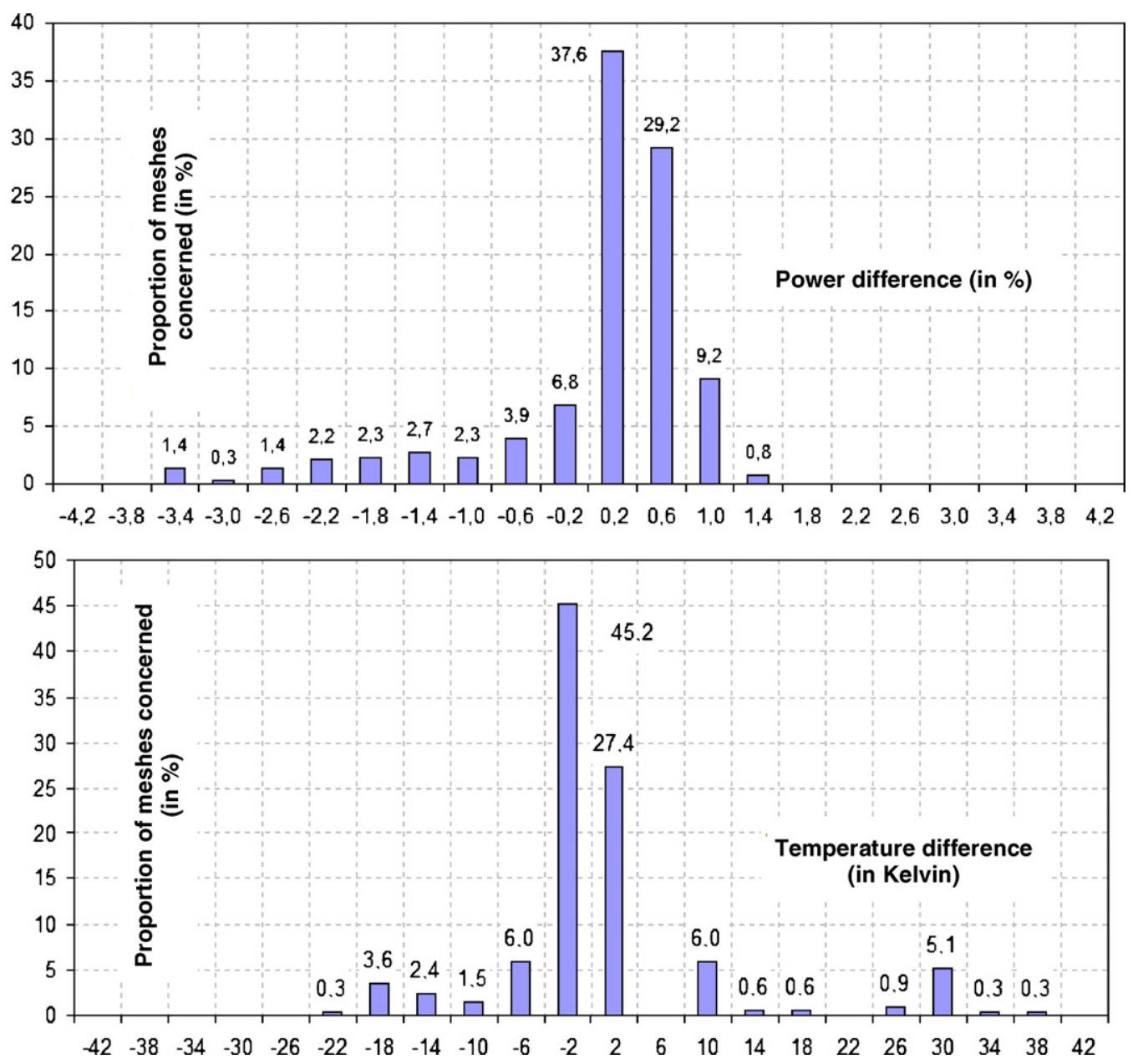

Fig. 17. Radial meshing study: N1 test configuration results compared to the reference ones. The differences are expressed in terms of percentages of the grid meshes with a certain level of power and temperature differences.

- Exchange of 6 radial power and temperature values for standard assemblies (32 for the control assemblies),

- Exchange of 1 or 5 power and temperature values for standard and control assemblies.

This optimal model is used today to calculate different steady state situation of the GTM-HR core reactor.

\subsubsection{Some neutronic and thermal-hydraulics results of the coupling system}

These results concern the coupling configuration defined in the last paragraph in Fig. 20. The convergence of the coupling iterative calculation is obtained when the variations of the $3 \mathrm{D}$ power and temperature distributions are less than $1 \%$ for the power and $1 \mathrm{~K}$ for the temperature (between two successive iter-

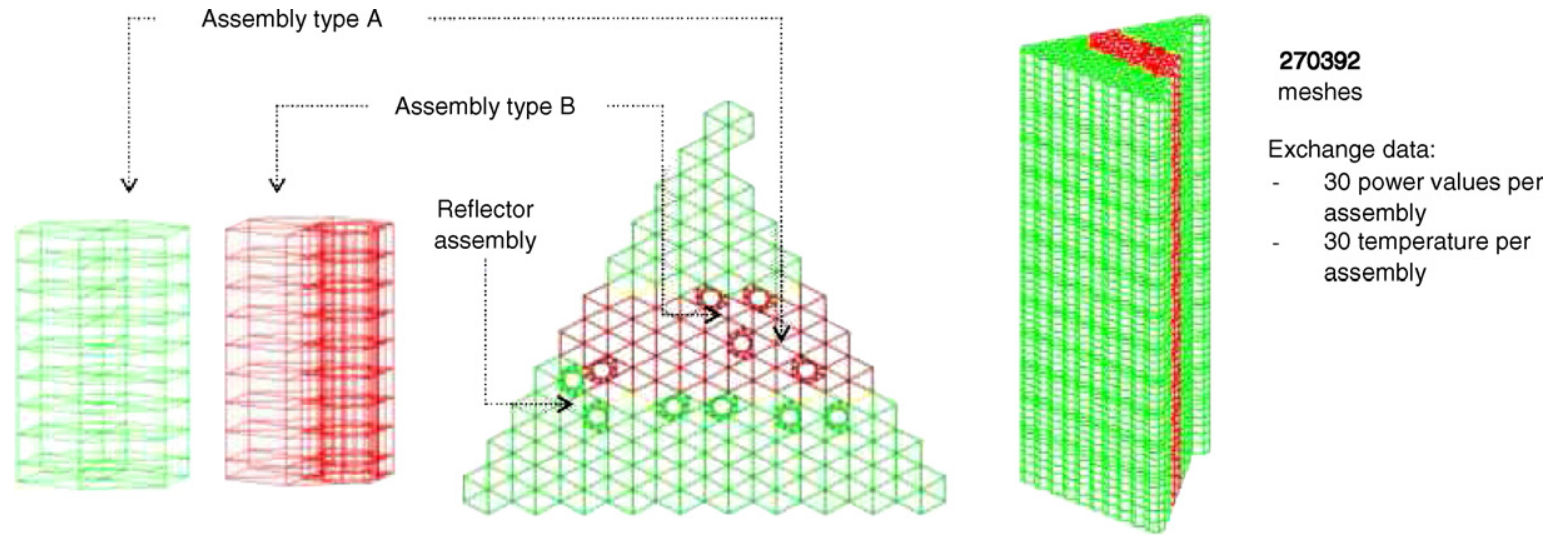

Fig. 18. Reference geometry for the axial meshing study (6 radial meshes and 5 axial meshes). 

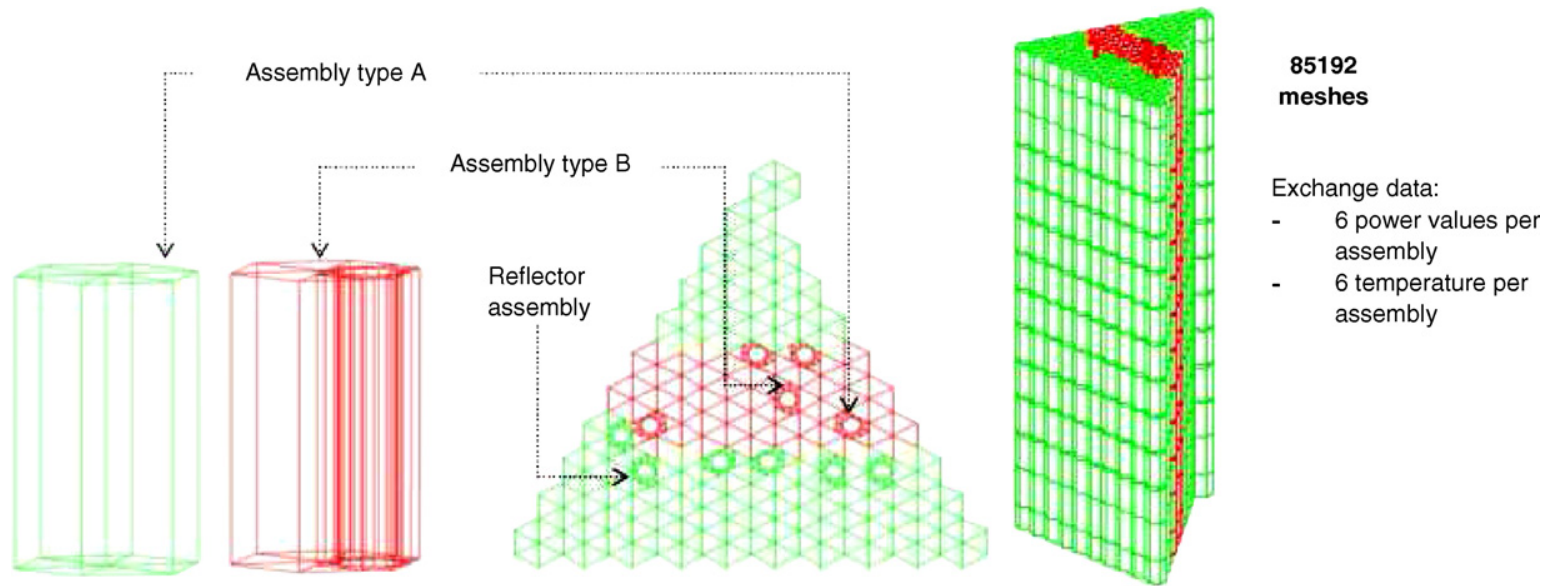

Fig. 19. Geometry of the examined test configuration.

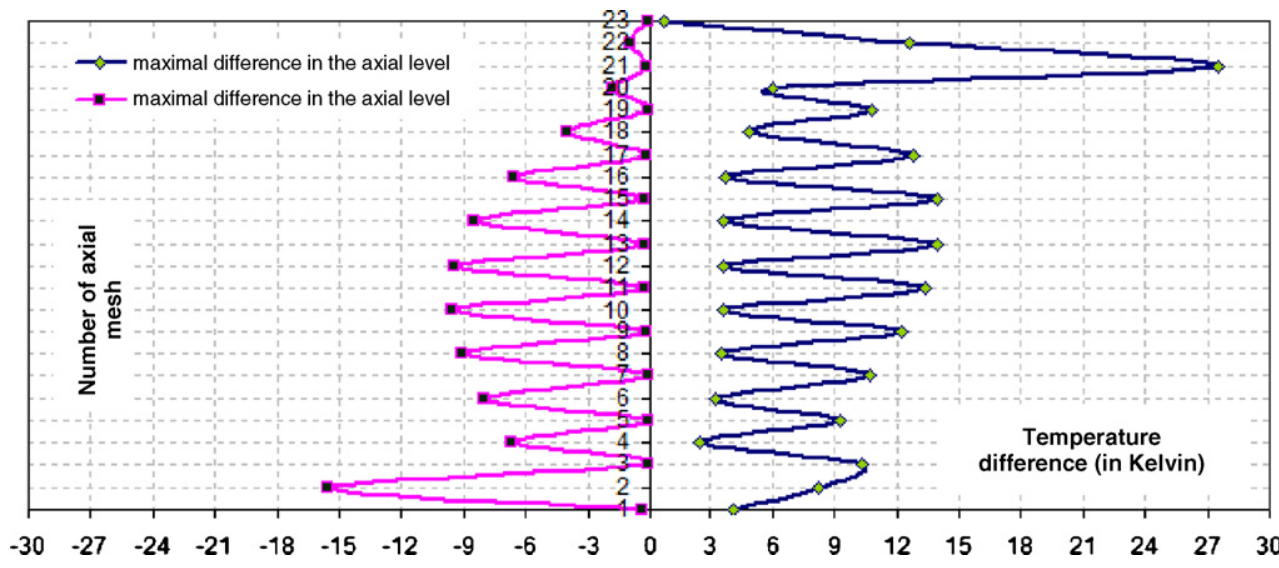

Fig. 20. Axial distribution of temperature differences between coarse and fine axial thermal-hydraulic grids.
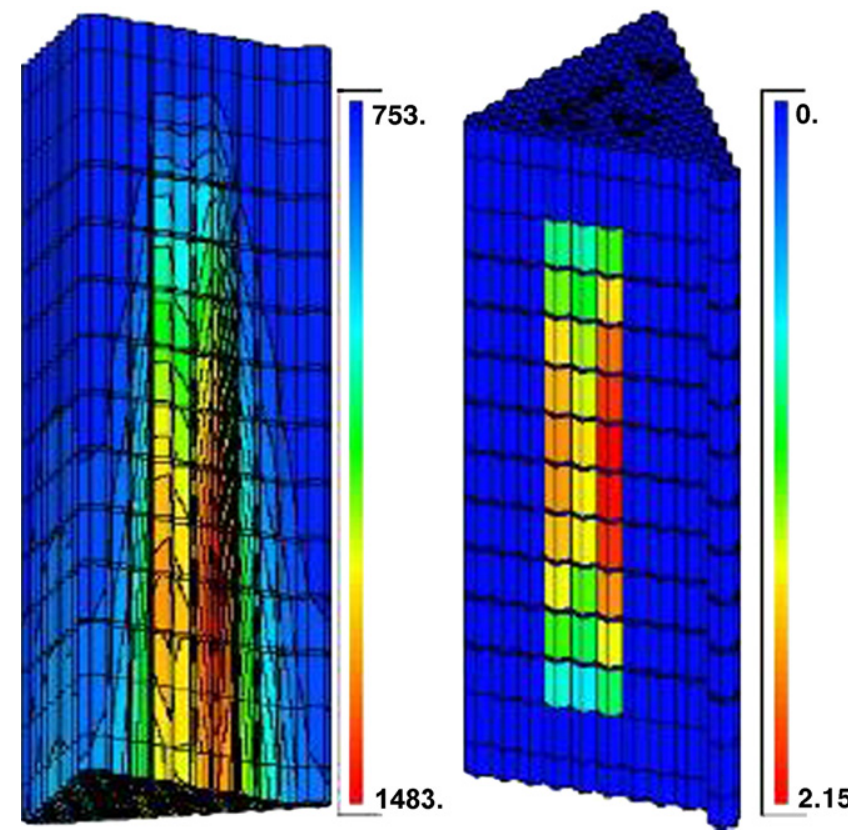

Fig. 21. 3D results (left: Solid temperature, right: Neutron power density). ation of the coupling calculation). Only some results are reported below. The temperature inside the core varies from 480 (helium inlet temperature at the top of the core) to $1210^{\circ} \mathrm{C}$ in the bottom of the core (Fig. 21). The hottest point of the core is located at $2.5 \mathrm{~m}$ above the bottom of the core. The thermal feedback impacts the axial power distribution. It induces a shift of the power peaking factot from the middle of the core (in a constant temperature hypothesis) to the top of the core (Fig. 21). The average helium temperature at the outlet of the core is $915^{\circ} \mathrm{C}$ ( $480{ }^{\circ} \mathrm{C}$ at the core inlet). In steady-state conditions, the helium power in the bottom of the core is $100 \mathrm{MW}$. Ninety-four percent of the energy is taken from the fuel assemblies, $4 \%$ from control rod cavity (large cavities where control rods are inserted) and $2 \%$ from the reflector by-pass. Helium velocity varies from 23 to $48 \mathrm{~m} / \mathrm{s}$. Due to thermal dilatation, the helium velocity is more important in the hottest region of the core.

\section{Conclusions}

This paper has described some flows and heat transfer models of the CAST3M/ARCTURUS code and applications to simulate the thermal-hydraulic behavior of gas cooled reactors (containment and in-vessel). Different models are available 
depending on the geometrical length scale. A thorough validation process is being conducted using basic separate effect tests, in-house experiments and international benchmarks. Surface radiation and interaction between convective and radiative heat transfer are important phenomena that have to be accurately modeled to quantify the different temperature levels or extracted power suitable to design, enhance the performance and ensure a high safety level of the different reactors. Containment thermal-hydraulics following a depressurization accident is also important to quantify pressure and thermal loads on components (guard containment) and to provide transient back-up pressure for the onset of natural convection inside the vessel (GFR concepts). This last point is a difficult task that will be investigated in the future with the CAST3M/ARCTURUS code. Coupling with neutronics is a key aspect of gas cooled reactors and CAST3M/CRONOS2 allows the study of these strongly coupled phenomena. Sensitivity studies have demonstrated the weight of the different parameters. Verification of this coupling will be the next step when some experimental results (HTTR) are available.

\section{References}

Dong, Y., Sun, Y., 2003. Benchmark problem of the HTR-10 steady state temperature distribution for the full power initial core. Tech. rept. INET.
Dong, Y., Sun, Y., 2004. Additionnal Informations to Benchmark problem of the HTR-10 steady state temperature distribution for the full power initial core. Tech. rept. INET.

Dumaz, P., Bassi, C., Cadiou, T., Malo, J.Y., 2005. The thermal-hydraulic studies in support to the GFR pre-conceptual design. NURETH-11 Conference, Paper 433, Avignon France.

Limaiem, I., Damian, F., Raepsaet, X., Studer, E., 2005. VHTR core modelling: Coupling between neutronics and thermal-hydraulics. MC2005 Conference, Paper 138, Avignon France.

Macnab, D.I., 1976. The CONTEMPT-G computer program and its application to HTGR containments. Tech. rept. GA-A12692A. General Atomic.

Melese, G., Katz, R., 1984. Thermal and Flow design of Helium Cooled Reactors. American Nuclear Society.

Poette, C., 2004. Advanced GCFR preliminary design $300 \mathrm{MWe}$ - Project status and trends for a higher unit power selection. ICAPP'04, Paper 4071.

Rademer, T., Bernnat, W., Lohnert, G., 2004. Coupling of neutronics and thermal-Hydraulics codes for the simulation of transients of pebble bed HTR reactors. In: Proceedings of the Conference on High Temperature Reactors, Beijing, China.

Reitsma, F., Strydom, G., de Haas, J.B.M., Ivanov, K., 2004. The PBMR steadystate and coupled kinetics core thermal-hydraulics benchmark test problems. Nucl. Eng. Des. 236, 657-668.

Studer, E., Coulon, N., 2003. Gas cooled reactor thermal-hydraulics using CAST3Mand CRONOS 2 codes. In: NURETH-10 Conference, Seoul Korea.

Studer, E., Dabbene, F., 2003. On the use of the MISTRA coupled effect test facility for the validation of containment thermal-hydraulics codes. In: NURETH-10 Conference, Seoul Korea.

Yadigaroglu, G., Andreani, M., Dreier, J., Coddington, P., 2003. Trends and needs in experimentation and numerical simulation for LWR safety. Nucl. Eng. Des. 221, 205-223. 